\title{
Use of Tilted Implants in Prosthetic Rehabilitation
}

\author{
Uso de Implantes Inclinados en la Rehabilitación Protésica
}

Pablo Naldini*; Enrique Fernandez-Bodereau** \& Laura Bessone*

NALDINI, P.; FERNANDEZ-BODEREAU, E. \& BESSONE, L. Use of tilted implants in prosthetic rehabilitation. Int. J. Odontostomat., 8(3):329-335, 2014.

ABSTRACT: Biomechanical measurements show that tilted implants, when part of a prosthetic support, avoid the use of distal cantilever units. This study included 20 women (78\%) and 12 men (22\%), aged over 50 years old (89\%), with a total of 156 implants. A delayed occlusal loading protocol was used and the average distal implant length and diameter were $10 \mathrm{~mm}$ and $4 \mathrm{~mm}$ respectively. Patients were followed up for 2 to 5 years after prosthesis connection. The aims of this study are to analyze the use of tilted implants in prosthetic rehabilitation of maxillae to reduce cantilevers length, and to study the biomechanical implications of implant-bone interface.

KEY WORDS: tilted implants, cantilever, edentulous maxillae.

\section{INTRODUCTION}

The rehabilitation of totally edentulous patients is very important for the restoration of the balance of the stomatognathic system. Several treatment modalities were identified for the fixed rehabilitation of the edentulous maxilla, with and without bone augmentation procedures. Regular, tilted, and zygoma implants are treatment modalities that do not require bone augmentation. However, another treatment possibility that requires bone augmentation procedures is the sinus floor elevation with interpositional bone grafts. Biomechanical measurements show that tilted implants, when part of a prosthetic support, avoid the use of distal cantilever units. The use of cantilevers is associated with a higher incidence of technical complications ( $21.6 \%$ with cantilevers vs. $10.3 \%$ ) (Sanz et al., 2009).

In the literature review, it was found that Bellini et al. (2009), observed in a prospective study that tilted configurations showed a lower absolute value of compressive stress compared with the non-tilted, indicating a possible biomechanical advantage in reducing stresses at the bone-implant interface. The results revealed biomechanical evidence that distal tilting of implants, splinted in full fixed prostheses without cantilevers, reduced the amount of stress generated around the peri-implant bone when compared to the levels of stress seen in peri-implant bone with vertical implants and cantilevered segments in similar full fixed prostheses (Mattsson et al., 1999).

The aim of this study is to analyze if the use of tilted implants in prosthetic rehabilitation of maxillae reduces the cantilevers length, avoids complex procedures of bone graft in the treatment of edentulous patients, and improves the biomechanical implications of implant-bone interface.

\section{MATERIAL AND METHOD}

This study is a retrospective trial performed in the Department of Oral Rehabilitation of the School of Dentistry. Patients were included according to our inclusion and exclusion criteria. 32 patients $(22 \%$ males and $78 \%$ female) participated in the trial, $28 \%$ were smokers, $89 \%$ of the subjects were over 50 years old, having an overall of 156 implants located in upper maxillae. The patients who received the treatment were in need of complete-arch rehabilitation, and presented a bone situation allowing for the placement of at least

\footnotetext{
*Assistant Professor, Department of Clinical Prosthodontics, Dental School, National University of Córdoba, Córdoba, Argentina. **Professor and Chair, Department of Clinical Prosthodontics, Dental School, National University of Córdoba, Córdoba, Argentina.
} 
four implants. The follow up period lasted from 2 to 5 years after prosthesis connection. Spearman correlation was used for statistical analysis to show any significant association.

A delayed occlusal loading pattern was used, and the average length and diameter of the distal implants was $12.3 \mathrm{~mm}$ and $3.82 \mathrm{~mm}$ respectively. Three implant systems were used: Standard plus (Straumann), Mk3 Branemark (Nobel Biocare) and Single stage (Biohorizons). An implant was considered tilted when the inclination was over 15 degrees with respect to the occlusal plane.

Patient Selection Criteria (Maló et al., 2006). The inclusion criteria for the recruitment of the patients were: 18 years or older; patients in general good health condition, able to undergo surgical treatment (ASA-1/ ASA-2); completely edentulous mandible or mandibular teeth with an unfavorable long-term prognosis; adequate bone height and thickness for the placement of implants at least $10 \mathrm{~mm}$ long and $4 \mathrm{~mm}$ wide without the need for bone augmentation procedures; and informed consent of the patient.

The exclusion criteria were: Presence of acute infection at the implant site; hematologic diseases; serious problems of coagulation; diseases of the immune system; uncontrolled diabetes; and metabolic diseases affecting bone, pregnancy, or lactation; Inadequate oral hygiene level (full-mouth plaque score and full-mouth bleeding score greater than $20 \%$ ) and poor motivation to maintain good oral hygiene throughout the study; Irradiation of the head or neck region, or chemotherapy within the past 60 months; Severe bruxism or clenching Exclusion criteria were; and Chemotherapy and radiotherapy.

Surgical Protocol. Antibiotics (amoxicillin $875 \mathrm{mg}+$ clavulanic acid $125 \mathrm{mg}$, Roemmers, Argentina) were given 1 hour prior the surgery and twice a day for 7 days thereafter. Chlorhexidine $0.12 \%$ mouthwash (PlacOut, Bernabo, Argentina) was indicated to be used the day before and for 15 days post surgery. After preparation of the patient the surgical procedures were performed under local anesthesia with Articaine $\mathrm{HCl}$. 4\% with Epinephrine 1:100,000 Injection (Sepyocaine ${ }^{\circledR}$ with epinephrine 1:100,000), Dexamethasone sodium phosphate and Dexamethasone acetate, injection (Duodecadrón, Sidus, Argentina). Anti-inflammatory and analgesic medication (Flurbiprofeno, $100 \mathrm{mg}$, Gador, Argentina) was administered during 4 days following the surgery.
Standard procedures were followed for placing the implants. Implant stability was achieved in all cases through a manual assessment. A mucoperiosteal flap was raised along the top of the ridge with relieving incisions on the buccal aspect in the molar area; the posterior implant tilting with about $30^{\circ}$ of inclination.

Prosthetic Protocol. The scheme was deferred after 3 or 4 months. The final prostheses were metal-ceramic and acrylic metal, $75 \%$ were screw retained and $25 \%$ cement. The prostheses have different length of cantilevers such as: $0 \mathrm{~mm}$ (without cantilever), $5 \mathrm{~mm}$, $10 \mathrm{~mm}$ and $15 \mathrm{~mm}$.

Follow-Up. Patients were frequently called during the early healing period and after prosthesis connection for detecting any signs or symptoms of inflammation/ infection in the treated sites. Patients were subsequently followed up from 2 to 5 years after the installation of the prosthesis as appropriate.

At follow-up examinations, intraoral radiographs were taken for evaluating bone levels and signs of periimplant pathology. Radiological control consisted in comparing the bone level at the time of prosthesis installation with the follow up period. The bone level and its resorption were measured in each implant digitalized radiograph through the Image pro-plus system.

Implant Survival and Failure Criteria. An implant was classified as surviving if: (1) it fulfilled its purported function as support for a full-arch reconstruction; (2) it was stable when tested manually; (3) no signs of infection were detected during clinical examination; and (4) no signs of peri-implant pathology were seen on the radiograph. Implants that did not meet the survival criteria were classified as failures (5).

\section{RESULTS}

Different variables such as sex, age, jaw, number of implants, length of cantilevers, bone level, restraint prosthetic, opposite dentition, history of periodontal disease as well as habits like smoking and bruxism were assessed.

The use of tilted distal implants to avoid or reduce the length of the cantilevers showed a success rate of $98.7 \%$ over a total of 156 implants, 92 axial medial implants (100\%) and 64 tilted distal implants (96.87\%) 
placed for 32 complete superior arches reconstruction. The success rate is $100 \%$ and $96.87 \%$ for axial and tilted respectively.

The study revealed two distal inclined implant failures. In the attempt to analyze and link the two failure implants with sex and age, it was noticed that the failures occurred in women over 50 years of age. Moreover, these patients had a history of periodontal disease and smoking (Fig. 1). Table I shows a significant association (Spearman correlation) between success and variables; setting a p-value of 0.05 for significant associations. Therefore, we interpret that the failure of at least one of the implants in patients is associated with the presence of periodontitis and smoking. By analyzing the number of implants supporting full fixed prosthesis we can observe that failures are

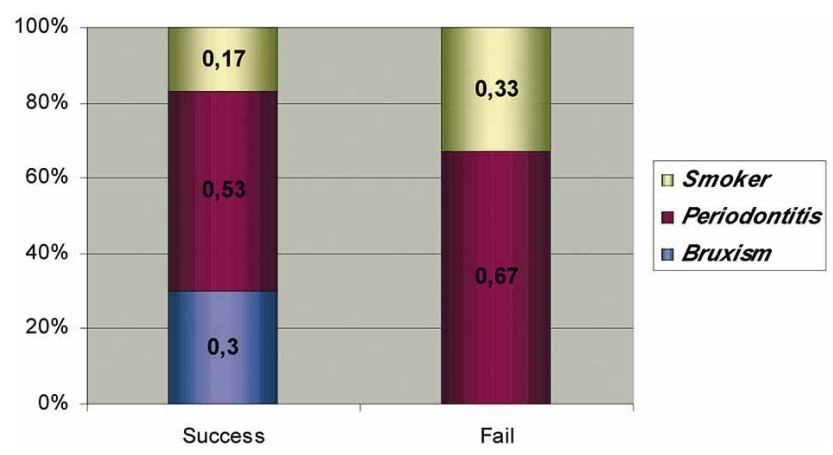

Fig. 1. The failure of at least one of the implants in patients is associated with the presence of periodontitis and active smoking status.

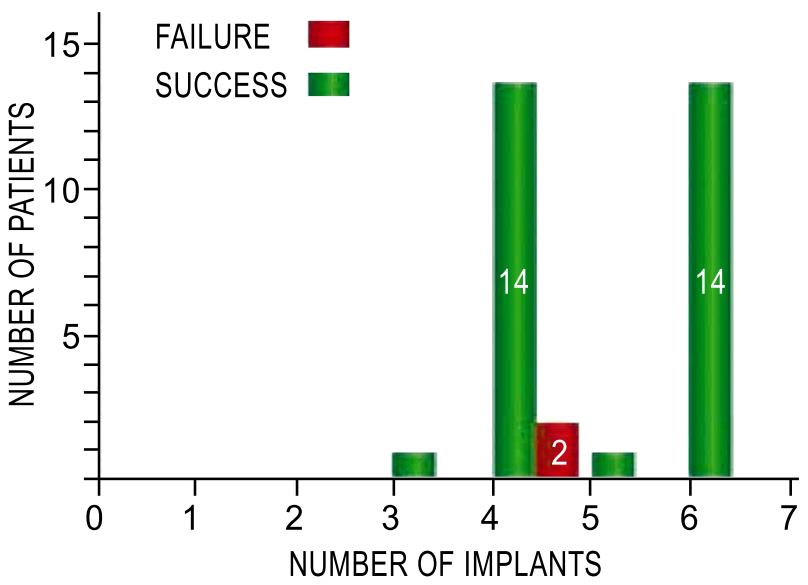

Fig. 2 shows the analysis of the number of implants which support a full fixed prosthesis. We can observe that failures are higher when there are 4 implants than when there are 6 . higher when there are 4 implants than when there are 6 (Fig. 2). In relation to the length of the cantilever the two distal implants failures are seen when the length is $15 \mathrm{~mm}$, compared to lengths of $0 \mathrm{~mm}$ (without cantilever), $5 \mathrm{~mm}$ and $10 \mathrm{~mm}$ (Fig. 3). When conducting the radiological control to compare the bone level at prosthesis connection time with the follow up period, an average loss of $0.35 \mathrm{~mm}$ can be observed presenting greater loss in patients with maladapted prosthetic structure at the distal implant and in those who smoke (over 15 cigarettes per day), $1.4 \mathrm{~mm}$ and $1.9 \mathrm{~mm}$ respectively. Both failed implants had screwed prostheses. Regarding opposite dentition, further studies are required to obtain meaningful data since it could not be appreciated in this protocol.

The complete protocol performed in one of the patients studied was shown in Figure 4.

Table I. Show a significant association (Spearman correlation) between success and variables; setting a p-value of 0.05 for significant associations. Therefore, we interpret that the failure of at least one of the implants in patients is associated with the presence of periodontitis and active smoking status.

$\begin{array}{lcc}\text { Success/Fail vs. } & \text { Spearman Coefficient } & \text { p-value } \\ \text { Bruxism } & 0.6246 & 0.0005 \\ \text { Periodontitis } & 0.6481 & 0.0003 \\ \text { Smoker } & 0.5674 & 0.0016\end{array}$

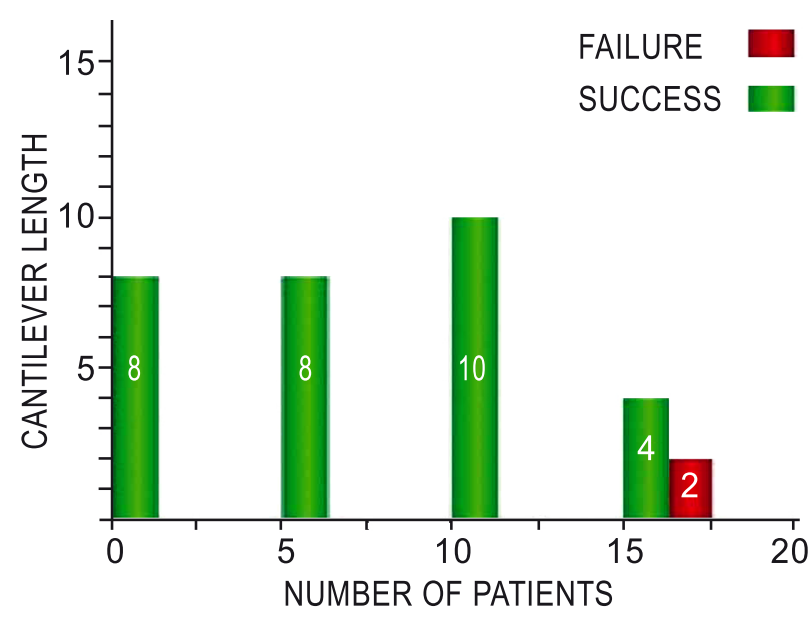

Fig. 3. In relation to the length of the cantilever the two distal implant failures are seen when the length is $15 \mathrm{~mm}$, compared to lengths of $0 \mathrm{~mm}, 5 \mathrm{~mm}$ and $10 \mathrm{~mm}$. 


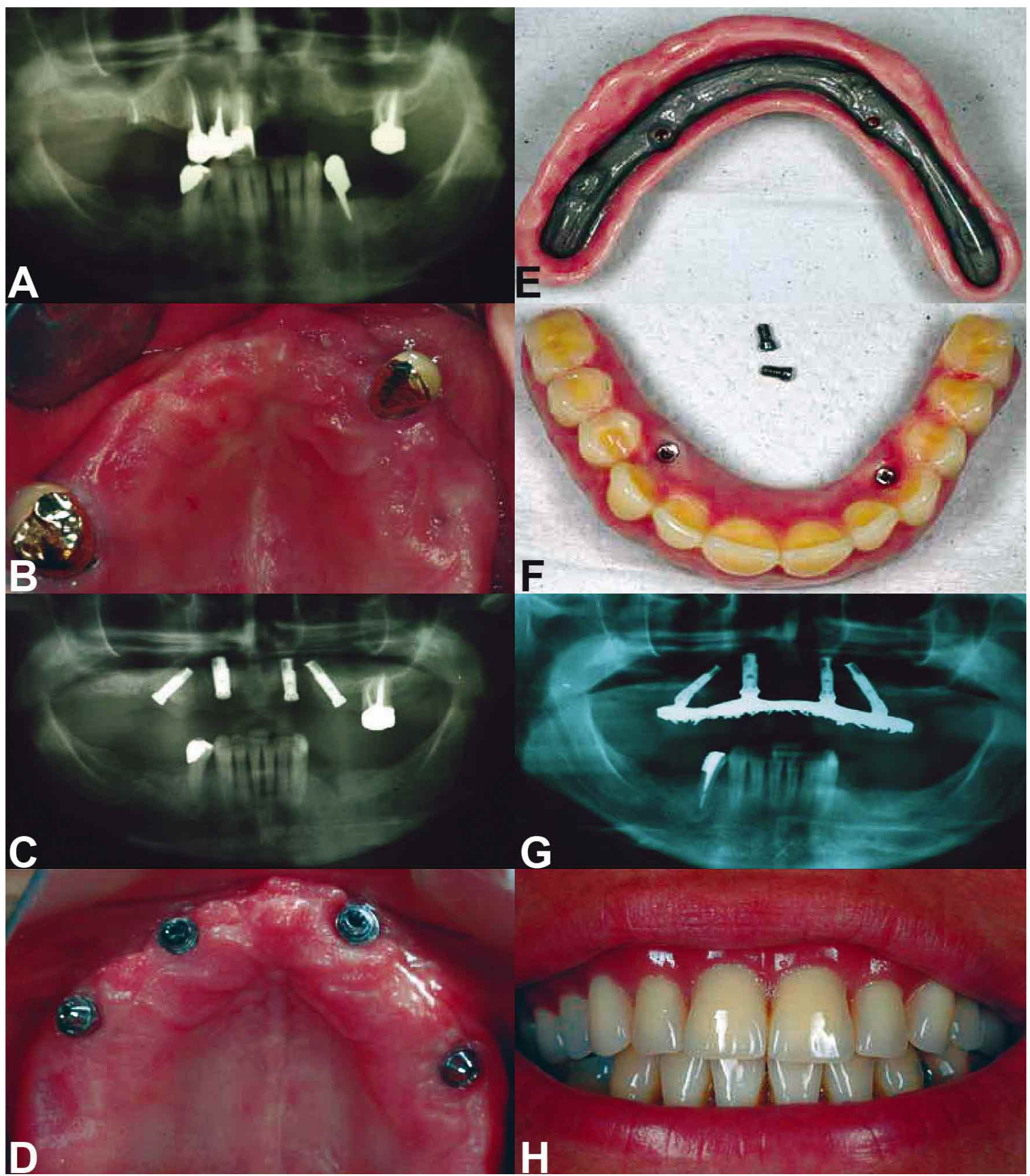

Fig. 4. A) Panoramic x-ray of one of the patients whose upper dental pieces were removed and four implants were placed, the tilted distal. B) Dental pieces were removed. C) Posterior x-ray view of the surgery to place the tilted distal implants that avoid the maxillary sinus. The upper molar had not been extracted yet. D) Clinical view of implants in the oral cavity. E) and F) view of screwed prosthesis with metal internalstructure. G) Panoramic x-ray view of the prosthesis placed in patient's oral cavity. H) Prosthesis placed in patient's mouth. View of Clinical resolution of the case. 


\section{DISCUSSION}

In the present study the use of tilted distal implants to avoid or reduce the length of the cantilevers showed a success rate of $98.7 \%$. The implants that failed were the two distal inclined, which may lead to conclude that they have more risk than axial, for their distal layout in the arch or inclined position. The success rate is $100 \%$ and $96.87 \%$ for axial and tilted respectively. These results are similar to the ones described by Calandriello \& Tomatis (2005), whose observations showed survival rates of $97.0 \%$ and $96.3 \%$ for the axial (33 implants, 1 failure) and tilted (27 implants, 1 failure) implants, respectively. The overall cumulative implant survival rate was $96.7 \%$. It has been shown by intraoral implant load measurements that tilting of an implant that is part of a multiple implant-supported bridge structure does not increase bone stress per se. Therefore, placing tilted implants in posterior maxillary locations has potential advantages over the more conventional straight implant alignment (Fortin et al., 2002).

To compare survival rate between deferred load and immediate load we can refer to the following study by Testori et al. (2008), in which the 1-year implant survival rate was $98.8 \%$ for both axial and tilted implants. Prosthesis success rate was $100 \%$ at 1 year. Marginal bone loss around axial and tilted implants at 12 -month evaluation was similar, being $0.9 \pm 0.4$ (SD) $\mathrm{mm}$ and $0.8 \pm 0.5$ (SD) $\mathrm{mm}$, respectively. The results of the present investigation are in line with previous clinical reports in which fixed bridges supported by four implants were successfully used for the early or immediate rehabilitation of fully edentulous mandibles. Several authors have also investigated the best position and inclination of implants. Krekmanov et al. (2000) note some biomechanical advantages of using tilted implants. They identified accomplishment of a wide anterior-posterior spread, avoidance of long cantilevers, and achievement of a favorable distribution of the occlusal load. It could also be speculated that tilted implants can be placed and anchored with greater cortical bone contact than axial ones; thereby achieving good primary stability (Krekmanov et al.; Maló et al., 2012; Jensen \& Adams, 2009; Ehsani et al., 2014).

Tilted fixtures may also be subjected to bending, possibly increasing the marginal bone stress. However, when the implant belongs to multiple implant supported prosthesis, the spread of the implants and the rigidity of the prosthetic structure should reduce the bending.
In a two-dimensional FE analysis, Zampelis et al. (2007) evidenced that distal tilting of implants splinted in a fixed restoration did not increase the stress in the marginal bone compared to axial implants.

According to some authors, a limited inclination of an implant (between 15 and 30 degrees) has no harmful effect for the load transfer to the surrounding bone (Herrmann et al., 2005).

Sex and age. In this study, it was noticed that both failures happened in women over 50. However, other authors describe sex and age as not showing significant differences regarding failure rates (Herrmann et al., 2003)

Periodontal background: Smoking and Bruxism. Patients with failures had a history of periodontal disease and smoking. We observed a significant association between success and these variables. Therefore, we interpret that the failure of at least one of the implants in patients is associated with the presence of periodontitis and smoking. Horwitz et al. (2008), indicate a potential influence of periodontal disease on the success rate of dental implants. Bone changes around immediately restored dental implants in periodontal susceptible patients were slightly higher than most reports in the literature.

Galindo-Moreno et al. (2005), found that on a sample of 514 implants in 185 patients, the peri-implant marginal bone loss was increased in 3 years in individuals consuming $410 \mathrm{~g}$ of alcohol daily and in tobacco users compared to those consuming less alcohol and no tobacco; thus, alcohol and tobacco consumption jeopardizes the outcome of restorative treatment with implant-supported prostheses. These patients had a mean peri-implant marginal bone loss of $1.66 \mathrm{~mm}$, very similar to our study in which a greater loss in smokers (over 15 cigarettes a day) $1.9 \mathrm{~mm}$ can be observed.

Number of implants. By analyzing the number of implants supporting full fixed prosthesis, it was observed that failures are higher when there are 4 implants than when there are 6. Herrmann et al., demonstrated that the number of implants supporting the restoration did not give any statistically significant difference. In agreement with our study, this author states that the highest failure was seen in the prosthesis 
supported by 4 implants whereas the failure rate decreased when either more implants or fewer implants per restoration were used (Herrmann et al., 2003).

Cantilever Length. In relation to the length of the cantilever, the two distal implant failures are seen when we have a length of $15 \mathrm{~mm}$, compared to lengths of 0 $\mathrm{mm}$ (without cantilever), $5 \mathrm{~mm}$ and $10 \mathrm{~mm}$. Bellini et al. (2009) concluded that no significant difference in stress patterns between the tilted $5 \mathrm{~mm}$ and the nontilted $15 \mathrm{~mm}$ configuration was predicted. The tilted configuration with a $15 \mathrm{~mm}$ cantilever was found to induce higher stress values than the tilted configuration with a $5 \mathrm{~mm}$ cantilever. This last study may support what was observed in our research.

Bone level. When conducting the radiological control to compare the bone level at prosthesis connection time with the follow up period, we observed an average loss of $0.35 \mathrm{~mm}$ for tilted implants. This is similar to the mean marginal bone resorption recorded by Calandriello \& Tomatis: which was low as $0.34 \mathrm{~mm}$ for tilted implants after 1 year. This result might be indicating lower stress in tilted implants in coincidence with Zampelis et al., who showed that distal tilting of implants splinted by fixed restorations does not increase bone stress compared to normally placed implants.

Peri-implant bone loss after 1-year follow-up could be evaluated in 30 patients $(n=60$ implants per group). Such difference was not significant $(p>0.05)$. At the 1-year visit, all implants were stable according to the opposing instrument pressure test. Theofilos Koutouzis \& Wennström (2007), studies failed to support the hypothesis that implant inclination has an effect on peri-implant bone loss.

Denture retention system. In our study, both failed implants had screw-retained prostheses. Vigolo et al. (2004), showed that within the limitations of that study, the results indicate that there was no evidence of different behavior of the peri-implant marginal bone and the peri-implant soft tissue when cemented or screwretained single-tooth implant restorations were provided for this patient population. For the method of retention (screw-retained versus cemented), no differences were found in implant success or survival rates between screw-retained and cemented restorations (Weber \& Sukotjo, 2007).

Opposite dentition. Meaningful data are not appreciated in this regard; further specific studies are required. In agreement with our study, Romeo et al. (2003), assessed two types of dentition opposite to the cantilever prostheses: natural teeth or fixed prosthesis supported by natural teeth (29 patients) and implantsupported prostheses (nine patients), mean values for these two groups were $0.72 \mathrm{~mm}$ and $0.78 \mathrm{~mm}$, respectively. Implant success rate was $97.2 \%$ and $100 \%$, respectively. Normal standardized distribution (considering 95\% confidence level) Z-test did not show any significant resorption difference between the two groups. Initial null hypothesis was confirmed.

\section{CONCLUSIONS}

The present study showed good clinical outcomes when using two tilted in combination with axial implants and a full fixed prosthesis for rehabilitation of the edentulous patients with atrophied maxillae. Minimal incidence of surgical complications and high implant survival rates, throughout the study suggest that the use of two tilted in combination with axial implants is a predictable technique for prosthetic rehabilitation of the edentulous patients. The study indicates that a biomechanically favorable prosthetic support may be obtained by tilting the posterior implants and that implant tilting per se has no negative effect on bone resorption. However, long-term data are needed to confirm this statement.

NALDINI, P.; FERNANDEZ-BODEREAU, E. \& BESSONE, L. Uso de implantes inclinados en la rehabilitación protésica. Int. J. Odontostomat., 8(3):329-335, 2014.

RESUMEN: Mediciones biomecánicas demuestran que los implantes inclinados, cuando son parte de un soporte de prótesis, evitan el uso de unidades distales en voladizo. Se incluyeron 20 mujeres (78\%) y 12 hombres (22\%), mayores de 50 años (89\%), con un total de 156 implantes. Se utilizó un protocolo de carga oclusal retardada, y la longitud y el diámetro promedios del implante a nivel distal distal, fue de $10 \mathrm{~mm}$ y $4 \mathrm{~mm}$, respectivamente. Los pacientes fueron seguidos durante 2 a 5 años después de la conexión de la prótesis. El objetivo de este estudio consiste en analizar el uso de los implantes inclinados en la rehabilitación protésica de maxilares para reducir la longitud de los voladizos, y estudiar las implicaciones biomecánicas de la interfase hueso-implante.

PALABRAS CLAVE: implantes inclinados, cantilever, maxilar desdentado. 


\section{REFERENCES}

Bellini, C. M.; Romeo, D.; Galbusera, F.; Agliardi, E.; Pietrabissa, R.; Zampelis, A. \& Francetti, L. A finite element analysis of tilted versus nontilted implant configurations in the edentulous maxilla. Int. J. Prosthodont., 22(2):155-7, 2009.

Calandriello, R. \& Tomatis, M. Simplified treatment of the atrophic posterior maxilla via immediate/early function and tilted implants: A prospective 1-year clinical study. Clin. Implant. Dent. Relat. Res., 7(Suppl. 1):S1-12, 2005.

Ehsani, S.; Siadat, H. \& Alikhasi, M. Comparative evaluation of impression accuracy of tilted and straight implants in All-onFour technique. Implant Dent., 23(2):225-30, 2014.

Fortin, Y.; Sullivan, R. M. \& Rangert, B. R. The Marius implant bridge: surgical and prosthetic rehabilitation for the completely edentulous upper jaw with moderate to severe resorption: a 5-year retrospective clinical study. Clin. Implant Dent. Relat. Res., 4(2):69-77, 2002.

Galindo-Moreno, P.; Fauri, M.; Avila-Ortiz, G.; Fernández-Barbero, J. E.; Cabrera-León, A. \& Sánchez-Fernández, E. Influence of alcohol and tobacco habits on peri-implant marginal bone loss: a prospective study. Clin. Oral Implants Res., 16(5):579-86, 2005.

Herrmann, I.; Lekholm, U.; Holm, S. \& Kultje, C. Evaluation of patient and implant characteristics as potential prognostic factors for oral implant failures. Int. J. Oral Maxillofac. Implants, 20(2):220-30, 2005.

Herrmann, I.; Lekholm, U. \& Holm, S. Statistical outcome of random versus selected withdrawal of dental implants. Int. J. Prosthodont., 16(1):25-30, 2003.

Horwitz, J.; Zuabi, O. \& Machtei, E. Radiographic changes around immediately restored dental implants in periodontally susceptible patients: 1-year results. Int. J. Oral Maxillofac. Implants, 23(3):531-8, 2008.

Jensen, O. T. \& Adams, M. W. The maxillary M-4: a technical and biomechanical note for all-on-4 management of severe maxillary atrophy--report of 3 cases. J. Oral Maxillofac. Surg., 67(8):1739-44, 2009.

Koutouzis, T. \& Wennström, J. L. Bone level changes at axialand non-axial-positioned implants supporting fixed partial dentures. A 5-year retrospective longitudinal study. Clin. Oral Implants Res., 18(5):585-90, 2007.

Krekmanov, L.; Kahn, M.; Rangert, B. \& Lindström, H. Tilting of posterior mandibular and maxillary implants for improved prosthesis support. Int. J. Oral Maxillofac. Implants, 15(3):405-14, 2000.

Maló, P.; Nobre, M. A.; Petersson, U. \& Wigren, S. A pilot study of complete edentulous rehabilitation with immediate function using a new implant design: case series. Clin. Implant Dent. Relat. Res., 8(4):223-32., 2006.
Maló, P.; de Araújo Nobre, M.; Lopes, A.; Francischone, C. \& Rigolizzo, M. "All-on-4" immediate-function concept for completely edentulous maxillae: a clinical report on the medium (3 years) and long-term (5 years) outcomes. Clin. Implant Dent. Relat. Res., 14(Suppl. 1):139-50, 2012.

Mattsson, T.; Köndell, P. A.; Gynther, G. W.; Fredholm, U. \& Bolin, A. Implant treatment without bone grafting in severely resorbed edentulous maxillae. J. Oral Maxillofac. Surg., 57(3):281-7, 1999.

Romeo, E.; Lops, D.; Margutti, E.; Ghisolfi, M.; Chiapasco, M. \& Vogel, G. Implant-supported fixed cantilever prostheses in partially edentulous arches. A seven-year prospective study. Clin. Oral Implants. Res., 14(3):303-11, 2003.

Sanz, M.; Naert, I. \& Working Group 2. Biomechanics/risk management (Working Group 2). Clin. Oral Implants Res., 20 (Suppl. 4):107-11, 2009.

Testori, T.; Del Fabbro, M.; Capelli, M.; Zuffetti, F.; Francetti, L. \& Weinstein, R. L. Immediate occlusal loading and tilted implants for the rehabilitation of the atrophic edentulous maxilla: 1-year interim results of a multicenter prospective study. Clin. Oral Implants Res., 19(3):227-32, 2008.

Vigolo, P.; Givani, A.; Majzoub, Z. \& Cordioli, G. Cemented versus screw-retained implant-supported single-tooth crowns: a 4-year prospective clinical study. Int. J. Oral Maxillofac. Implants, 19(2):260-5, 2004.

Weber, H. P. \& Sukotjo, C. Does the type of implant prosthesis affect outcomes in the partially edentulous patient? Int. J. Oral Maxillofac. Implants, 22(Suppl.):140-72, 2007.

Zampelis, A.; Rangert, B. \& Heijl, L. Tilting of splinted implants for improved prosthodontic support: a two-dimensional finite element analysis. J. Prosthet. Dent., 97(6 Suppl.):S35-43, 2007.

Correspondence to:

Dra. Laura Bessone

Assistant Professor

Department of Clinical Prosthodontics

Dental School

National University of Córdoba

Córdoba

ARGENTINA

Email: laurabessone@hotmail.com

Received: 11-05-2014

Accepted: 08-08-2014 